\title{
Review
}

Neuropsychobiology

Neuropsychobiology 2011;64:141-151

DOI: $\underline{10.1159 / 000328947}$
Received: April 1, 2009

Accepted after revision: August 11, 2009

Published online: July 29, 2011

\section{Sleep Deprivation in Mood Disorders}

\author{
Francesco Benedetti Cristina Colombo \\ Department of Clinical Neurosciences, Scientific Institute and University Vita-Salute San Raffaele, Milan, Italy
}

\begin{abstract}
Key Words
Sleep deprivation · Antidepressant • Bipolar disorder •

Major depression · Mania · Light therapy
\end{abstract}

\begin{abstract}
Growing clinical evidence in support of the efficacy and safety of sleep deprivation (SD), and its biological mechanisms of action suggest that this technique can now be included among the first-line antidepressant treatment strategies for mood disorders. SD targets the broadly defined depressive syndrome, and can be administered according to several different treatment schedules: total versus partial, single versus repeated, alone or combined with antidepressant drugs, mood stabilizers, or other chronotherapeutic techniques, such as light therapy and sleep phase advance. The present review focuses on clinical evidence about the place of SD in therapy, its indications, dosage and timing of the therapeutic wake, interactions with other treatments, precautions and contraindications, adverse reactions, mechanism of action, and comparative efficacy, with the aim of providing the clinical psychiatrist with an updated, concise guide to its application.
\end{abstract}

Copyright @ 2011 S. Karger AG, Basel

\section{Introduction}

Sleep deprivation (SD) is a core component of psychiatric chronotherapeutics, defined as the controlled exposure to environmental stimuli that act on biological rhythms in order to achieve therapeutic effects in the treatment of psychiatric conditions [1]. The use of SD in everyday psychiatric practice is fairly new, and is almost exclusive restricted to the treatment of mood disorders. These techniques include manipulations of the sleepwake rhythm (such as partial and total SD and sleep phase advance) and of the exposure to the light-dark cycle (light therapy, dark therapy) [2], and have been developed either directly from neurobiological models of behavior, as in the case of light and dark therapy, or by monitoring rapid antidepressant effects after prolonged wake, as in the case of SD [3].

After the initial descriptions of its rapid and powerful effects [4], the use of SD has long been restricted to experimental settings, in the context of research aimed at studying the mechanisms of action of this treatment in order to deepen our knowledge on the pathophysiology of depression [5]. Application in common clinical practice was discouraged by the early observation that SD is acutely followed by an abrupt mood improvement after a single night awake, but that a depressive relapse is expected after the restoration of normal sleep [6]. In recent years, however, something changed: (1) increased neurobiological knowledge on the functioning of the biological clock led researchers to hypothesize that internal timing is a key factor to mental health [7], and triggered increased interest in treatments directly targeting its basic functioning [8], and (2) the continuous development of new clinical strategies for the chronotherapeutic treatment of depression and their combination (e.g. SD plus light therapy) or their association with antidepressant drugs and mood stabilizers led to long-term remissions [9].

\section{KARGER}

Fax +4161306 1234

E-Mail karger@karger.ch

www.karger.com (c) $2011 \mathrm{~S}$. Karger AG, Basel

0302-282X/11/0643-0141\$38.00/0

Accessible online at:

www.karger.com/nps
Dr. Francesco Benedetti

Dipartimento di Neuroscienze Cliniche

Istituto Scientifico Universitario Ospedale San Raffaele, San Raffaele Turro

Via Stamira d'Ancona 20, IT-20127 Milano (Italy)

Tel. +39 022643 3156, E-Mail benedetti.francesco@ hsr.it 
Thus, while many papers reviewed data on the effects of SD and, in some cases, proposed it as an experimental model of antidepressant treatment [2, 6, 10-15], few authors reviewed evidence on its clinical use against depression $[1,9,16,17]$. The aim of the present review is to provide an updated concise clinical guide on SD in the treatment of mood disorders.

\section{Place of SD in Therapy}

The magnitude of improvement after one night of SD is often equal to that observed after 6 weeks of antidepressant medication, for example, a $50 \%$ or greater reduction in the scores on the Hamilton Rating Scale for Depression (HRSD) and a final HRSD <9 [13]. Mainly developed in European countries over the last 5 decades, this technique evolved both from empirical observations of impressive clinical changes following random exposure to environmental stimuli (e.g. immediate mood improvement in depressed patients deprived of sleep by chance) [18], and from neurobiological models of behavior tested in preclinical experimental settings [19].

The reported response rates are similar to those observed with antidepressant drugs, ranging from 50 to $80 \%$ of treated patients [1], but with the difference that the response becomes clinically relevant in a matter of hours after the beginning of treatment (i.e. the day after) without the long response latencies usually associated with antidepressant drugs $[1,6,15]$.

The therapeutic target is the broadly defined depressive syndrome. While the majority of normal subjects experience no changes or a worsening of mood after SD [20], patients affected by primary or secondary major depression usually experience some degree of improvement [16]. Thus, positive antidepressant effects of SD have been reported in endogenous, reactive, unipolar, bipolar, secondary, and schizoaffective depression [16], in depression in the elderly [21] and secondary to Parkinson's disease [22] or schizophrenia [23], and in depression associated with pregnancy and postpartum [24] and premenstrual dysphoric disorder [25].

Nevertheless, a diagnostic criterion should be used to define indications because, when directly comparing psychiatric conditions, better effects have been observed in endogenous primary depression compared with reactive and/or secondary depression [26], and in the treatment of bipolar disorder compared to primary depressive disorder [27]. Age is not an issue [28, 29].
Based on the available literature, the primary indication for antidepressant SD treatment should then be a major depressive episode in the course of bipolar disorder, but the clinical psychiatrist can use this technique in all depressive conditions based upon clinical need.

\section{Dosage and Timing of the Therapeutic Wake}

\section{Duration of Wake}

It is still unclear how many hours of SD are needed to achieve its full antidepressant effect. A typical antidepressant SD treatment begins with the extension of daytime wake into the night, and lasts about $36 \mathrm{~h}$ until the evening of the day after, when sleep is again allowed (socalled 'total' SD because wake is prolonged throughout the night of treatment). Given the simple schedule and the powerful effects in the absence of side effects, the effects of total SD are best documented in the literature compared to those of other sleep restriction modalities $[13,30]$.

During this extended wake, a turning point of mood common to all patients has not been demonstrated, but existing studies suggest that the antidepressant effects of SD do not occur before the end of the night awake [31] and become clinically evident when the patient is exposed to daytime light, after the night awake, or earlier during the night, if the SD is carried out in bright light [32].

During the prolonged wake, it is suggested that the patients remain awake without napping, in order to avoid the depressive relapse that follows recovery sleep, but while some researchers reported a mood worsening after napping [33] or even after subjectively unrecognized microsleeps [34], others did not, or even reported a mood amelioration after napping [35], or suggested a circadian variation in the propensity to relapse into depression as a function of nap timing (worse in the morning, but with longer naps paradoxically less detrimental than shorter ones) [36]. It is then still debated if a short nap can block the powerful antidepressant effects of SD. Available data suggest that this interaction may be linked with yet undefined individual characteristics (possibly including the individual turning point of mood) and that a full response to SD can well occur independent of napping.

This hypothesis is sustained by the observation that SD can be limited to a part of the night, and nevertheless obtain clear antidepressant effects in as much as $75 \%$ of treated patients (so-called 'partial' SD because sleep is allowed during one-half of the night) [37]. The observation 
that partial SD late in the night was followed by response rates similar to those obtained after total SD led to propose it as the SD method of choice [38], but the issues of efficacy, timing and stress are yet debated [17]. Despite similar overall response rates, studies directly comparing total and partial SD found indeed total SD to be more effective than partial SD [39]. Moreover, it is not selfevident that to be awakened during the second half of the night (e.g. at 02:00-03:00 $\mathrm{h}$ in the morning) and stay awake until the following evening is less stressful than spending the whole night awake, and studies assessing the degree of stress linked with the different treatment modalities are lacking. Regarding the issue of timing for partial SD (first or second part of the night), trials specifically addressing the issue of comparative efficacy showed either that late partial SD was more effective than early partial SD, thus suggesting that both time and duration of sleep affected treatment response [40]; or that early and late partial SD had similar efficacy, thus suggesting that sleep reduction as such, and not the time at which it takes place, correlated with the therapeutic effect of SD [41].

The minimum amount of sleep restriction needed to obtain antidepressant effects has not been determined, but very short SD schedules, such as a 2-hour sleep restriction in the middle of the night, have been shown to produce little clinical effect [39].

Finally, the early hypothesis that the therapeutic effect of $\mathrm{SD}$ is linked with the deprivation of rapid eye movement (REM) sleep is now questioned given that the early report of better antidepressant effects in selective REM sleep-deprived patients [42] has not been replicated by a recent comparative study which showed that the antidepressant effect of REM sleep-disrupting awakenings was similar to that of aspecific stage II or slow wave-sleep disruption [43]. Moreover, despite its similarity with the REM sleep-suppressing effect of some antidepressant drugs [44], selective REM SD was never used in clinical practice, and its specific usefulness thus remains hypothetical.

\section{Repetiton of Treatment}

Repetition of treatment is allowed, and can lead to progressively better effects. Our group developed a treatment schedule based on repeated total SD, three times a week, resulting in a lengthening of the sleep-wake period from the usual 24 to $48 \mathrm{~h}$ [1,45-52]. Each SD cycle is composed of a period of $36 \mathrm{~h}$ awake, and on the 1st, 3rd and 5th day, patients are totally sleep deprived from 07:00 h until $19.00 \mathrm{~h}$ of the following day. They are then allowed to sleep during the night of the $2 \mathrm{nd}$, 4 th and 6 th day. SD is carried out in normal ambient light, but patients are administered light therapy during the SD night, to counteract sleepiness, and in the morning after recovery sleep, half an hour after awakening, between 8 and 9 a.m. from day 1 to day 7 .

Many other schedules for repeat treatment have been proposed: e.g. partial SD repeated once a week for 3 weeks [53], or 3 times a week [54], or twice a week for 2 weeks [55], or 3 times a week for 2 weeks [56], or 5 times at 5-day intervals [57], or 6 times at 4- to 5-day intervals [58]; or total SD twice a week [59], or twice a week for 3 weeks [60, 61] or for a month [62], or twice a week followed by partial SD twice [63], and so on. Repeated total SD once a week has also been proposed as a prophylactic treatment, to sustain response and prevent relapses [64, 65].

Direct comparisons, however, are very scarce. In a crossover trial, the comparison of partial SD once versus twice a week for 2 weeks failed to find a difference in the magnitude of the antidepressant effects [66]. Given, however, that response to a single SD is not generalizable to a series of SDs in an individual [60], a patient may well not respond to the first SD and respond to the second one, and this pattern is of high clinical importance. Evaluation of the comparative efficacy of these different treatments is then prevented, and what is still undefined, and highly needed in a clinical perspective, is a reliable assessment of a dose-response relationship between amount, timing and repetition of wake therapy and extent and duration of the clinical antidepressant response.

\section{Recovery Sleep and Relapse}

Obviously, wake cannot last indefinitely, and SD ends with recovery sleep. In reported trials, recovery sleep is free and undisturbed, with the patient choosing the most appropriate bedtime and waking up when the night sleep ends spontaneously. Actigraphic evidence showed that after total SD patients significantly anticipate bedtime and sleep onset, and sleep more and better than before treatment (when sleep was usually disturbed by depressive insomnia) [52].

According to early descriptions of the clinical effects of $\mathrm{SD}$, relapse is expected in the morning after awakening from recovery sleep, even when a complete response had been achieved the evening before $[6,16]$. The depressive syndrome usually manifests itself with a lower degree of severity than before treatment, and some objective improvement in mood and cognition is maintained $[67,68]$, but in the following days, patients tend to show progressive worsening and the severity of depression returns to 
the levels observed at baseline. Recovery sleep does not necessarily lead to relapse on the first day after SD [17], and a small subgroup of patients (10-15\%) shows an atypical improvement on the day after recovery sleep instead of improving immediately after their night wake [41]: nevertheless, in the following days, mood is expected to progressively deteriorate [6].

Repetition of the treatment leads to a typical sawtooth pattern with repeated ameliorations after SD and repeated relapse after recovery sleep [47], with little net benefit at the end. The trend toward amelioration due to incomplete relapses, when present, is expected to reverse within a few weeks after a regular restoring of the usual 24-hour sleep-wake cycle, and in the absence of combined treatments only a $5-10 \%$ of bipolar depressed responders achieve sustained remission from their depressive episode $[46,48]$.

\section{Interactions with Other Treatments: The Need for Combined Antidepressant Strategies}

Considering the almost inevitable risk of early depressive relapse after SD treatment, combined antidepressant and mood-stabilizing strategies are needed to achieve sustained clinical effects.

Total or partial, single or repeated antidepressant SD has been successfully associated with the selective serotonin reuptake inhibitors fluoxetine [45], paroxetine [29, $69,70]$ and sertraline $[71,72]$, the dopaminergic amineptine [49], the mixed serotonergic-noradrenergic tricyclic antidepressants amitriptyline $[58,66]$ and clomipramine [73-77] and the noradrenergic tricyclic nortriptyline [78]. The effect is synergistic: SD hastens the antidepressant action of drugs or, conversely, drugs sustain the transient antidepressant effects of SD over time. Whichever the interpretation, the clinical trials consistently show that a stable clinical euthymia is achieved by the majority of patients $[1,2,10]$. A negative interaction has only been reported when SD was combined with trimipramine [79], which shows in vitro DA antagonistic properties [80]. Combined SD and antidepressant treatment not only improves the depressive syndrome, it also exerts a beneficial effect on overall quality of life; partial SD combined with sertraline caused a faster improvement in WHOQoL scale scores than sertraline monotherapy [71].

Lithium salts are the mainstay of the treatment of bipolar disorder, and sustain the antidepressant effects of SD as well [81, 82]. Continuing lithium in the usual therapeutic range leads to sustained remission over the months, and stable euthymia is then obtained in the majority of patients without the need for other psychotropic drugs $[47,48,50]$. Lithium not only sustains response to $\mathrm{SD}$, but it enhances it as well, probably by overcoming the effect of unfavorable genetic predispositions which affect the functioning of the serotoninergic system [83].

Finally, to enhance and sustain its effects in the days immediately following treatment, SD has been combined with other chronotherapeutic techniques. Several independent trials consistently reported synergistic effects of the combination of SD with light therapy $[48,50,84,85]$ and/or subsequent sleep phase advance [77, 86-89].

\section{Precautions and Contraindications}

\section{Delusional Depression}

The presence of psychotic symptoms should be carefully evaluated. Major depressive episodes with psychotic features constitute a severe disability, hence the necessity to obtain a rapid amelioration of symptoms, and SD could be a good candidate to pursue this aim. Literature evidence is sparse, however, and suggests caution in administering SD to psychotic depressed patients. One group reported that depressives with psychotic features reacted more favorably than nonpsychotic depressives to total SD combined with clomipramine, but also that more marked negative responses were observed after recovery sleep (either unlimited or partial sleep) in psychotic versus nonpsychotic depressives [90, 91]. Anecdotal reports on delusional depressed patients treated with SD showed that in some cases an 'increased intensity of drives' after SD was paralleled by a worsening of psychotic symptoms [92], that 1 patient switched polarity after combined SD and tricyclic medication, while another, treated with combined SD and neuroleptics, showed a moderate improvement [93] and that the average response in 3 psychotic depressives treated with total SD and placebo was positive [94]. Our group treated 5 patients with total SD, in the absence of concomitant drugs, and observed a worsening of overall symptomatology including increased extension and pressure of delusions [95]. In the absence of balanced controlled trials, no definite conclusion can be drawn on this topic, but caution and a careful antipsychotic strategy, possibly including combined medications, is suggested by the available literature.

\section{Mixed States}

'Pure' depression and mania are not the only psychopathological conditions that affect bipolar patients, who 
may also experience mixed states in which symptoms pertaining to both conditions are simultaneous. The current clinical management of these episodes relies on the classical ex adjuvantibus medical reasoning more than on complex psychopathological discussions: mixed states show good response to antimanic treatment, with particular sensitivity to antiepileptic mood stabilizers [96]. Current guidelines on diagnosis and treatment assimilate mixed states to bipolar mania and suggest to avoid antidepressants because they may worsen intraepisodic mood lability [97].

In case of a mixed episode with prevalent depressive symptoms, the administration of antidepressant SD will precipitate mania. Given that mania can be a less threatening condition than a psychotic mixed state, this strategy has been suggested as useful in clarifying diagnostic conundrums and define treatment options in clinical conditions such as puerperal psychosis, when categorical diagnosis is uncertain and rapid treatment is needed [98]. However, given that sleep loss could have a causal role in the development of postpartum psychosis [99], caution is strongly suggested in using this approach.

\section{Medical and Neurological Conditions}

SD is a stressor [100], and should thus be preceded by a medical examination aimed at ruling out the presence of medical conditions that can be worsened by even low degrees of stress. The unspecific stress associated with staying awake all night could unexpectedly precipitate unsuspected medical conditions, e.g. undetected severe cardiovascular diseases [101, 102].

Sleep is a potent activator of interictal epileptiform discharges, and SD is a trigger of epileptic seizures [103]. The relationship between changes in synaptic efficacy during the sleep-wake cycle, epilepsy [104] and the therapeutic effect of SD [5] is still unclear, and there is a lack of data about the possible efficacy of SD in patients treated with antiepileptic drugs at therapeutic levels. A significant association was reported between antidepressant response to SD and to a trial of carbamazepine, but it is unclear whether this relationship was based on antidepressant response to any agent or was specific to carbamazepine [105].

In Parkinson's disease, contrasting results have been reported. A higher lifetime sleep duration has been associated with a higher risk of developing this disease, while rotating shift work and sleep loss had a protective effect [106]. Probably due to the marked increase in dopaminergic neurotransmission associated with SD, sleep-deprived patients affected by Parkinson's disease temporar- ily improved their motor scores after total $[22,107,108]$ or partial SD [109], and the improvement in motor symptoms was associated with a more prolonged amelioration of depression [110]. In subgroups of patients, however, a sleep benefit and a worsening after SD have been reported [111], and caution should thus be used in administering antidepressant SD to patients with Parkinson's disease.

Partial SD has been successfully used to treat depression during pregnancy, when the use of psychotropic drugs is discouraged [24]. A history of sleep disruption in the latter stages of pregnancy has been associated with the development of postnatal blues [112], but it is unclear whether sleep perturbation, with its associated changes in the sleep-immunity relationship [113, 114], has an etiological role or is an early symptom of the depressive syndrome which fully develops after childbirth. In the absence of clear-cut evidence, caution should be exerted in administering $\mathrm{SD}$, as any other stressor, to pregnant women.

\section{Adverse Reactions}

\section{Sleepiness}

The most common and obvious adverse effect of SD is daytime sleepiness, and patients treated with SD should be advised not to engage in dangerous activities which require attention and concentration (e.g. driving a car). The degree of sleepiness shows high individual variability, and anecdotic reports and lay observations described patients who could continue their daytime job activities despite having stayed awake all night due to an antidepressant SD treatment [115]. Considering the large literature about sleep loss and the increased risk of accidents, however, patients should be protected from these easily avoidable risks [1].

Recently, the combination of wake-promoting substances, such as flumazenil, has been proposed to reduce sleepiness and to improve antidepressant response by suppressing microsleeps $[34,116]$. Carrying out the treatment in a hospital setting, as in most reported trials, can, however, prevent the consequences of this unavoidable adverse effect.

\section{Manic Switches}

In euthymic patients affected by bipolar disorder, abrupt changes in the sleep-wake rhythm can trigger mania through a self-reinforcing mechanism of sleep loss and progressive mood improvement, which leads to the 
typical increase in activity, reduced need for sleep, and eventually the full manic syndrome spinning out of control $[117,118]$. Indeed, when treating rapid-cycling bipolar depressed patients a high rate of manic switches is expected after SD [119] as well as after any antidepressant medication.

In non-rapid-cycling patients affected by bipolar disorder type I, very low switch rates have been observed in reported trials. In an early review on the effects of SD in depression [6], a $30 \%$ switch rate was reported, based on 10 studies published between 1974 and 1982. When examining more recent studies on the effects of SD, switches into mania disappear from literature reports except when considering rapid-cycling bipolar patients [120]. It is possible that the widespread diffusion of lifetime mood-stabilizing therapeutic strategies could have contributed to this favorable evolution over the decades. Regarding the bipolar rapid-cycling condition, the spontaneous occurrence of SD before switches into manic phases was observed in 13/15 rapid-cycling bipolar patients, while therapeutic SD caused 7/9 drug-free depressed rapid cyclers to switch into mania [119]: no doubt that the administration of therapeutic SD in this particular subgroup of patients causes the same switch rate into mania that is expected to occur naturally with spontaneous SD in the illness course.

On the other hand, in 206 bipolar depressed inpatients treated with serial repetition of total SD, we observed a $4.85 \%$ switch rate into manic phase, and a $5.83 \%$ switch rate into hypomanic phase [120]: these switch rates are closely similar to those observed with selective serotonin reuptake inhibitors and placebo, are lower than those reported with tricyclic antidepressants [121] and are much lower than the reported $10-29 \%$ manic switches in patients affected by bipolar disorder and administered maintenance treatment with antidepressants $[122,123]$. Moreover, the severity of mania was rather mild or moderate in the majority of our patients, and less than one half needed to combine antipsychotic medication to mood stabilizers to return to euthymia: since manic symptoms appeared during hospitalization, patients were immediately administered a medication, and restoration of night sleep with intravenous benzodiazepines resulted in a rapid resolution of manic symptomatology in one third of the patients; another third developed a manic phase which resolved within 1 month with mood stabilizers, and roughly the last third developed a full manic episode with psychotic features and needed neuroleptic medication. All patients with hypomanic symptoms returned to euthymia with lithium salts and benzodiazepines alone [120].
Two factors should be considered to explain this good prognosis of mania induced by therapeutic SD. First of all, this 'mania' does not fulfill the DSM-IV temporal criterion of mania because symptoms are expected, observed and treated at their very onset, and the clinical characteristics of the 'episode' can thus not be compared with those reported in trials on bipolar mania. Second, the clinical situation is very different from that of patients who have already completed the closed-loop feedback between sleep loss and behavioral activation [117, 124-126]: clinical evaluations of the relationship between sleep loss, perturbation of the activity-rest cycles and light-dark exposure, and manic psychopathology, consistently confirmed that at the beginning of mania (but not thereafter), sleep loss directly triggers and augments mania [127], and sleep and dark exposure rapidly stop it [128].

The risk of a manic switch after therapeutic SD thus seems to be low, preventable, and with easily treatable consequences, and should not be regarded as a contraindication except in the case of rapid-cycling patients when, based on previous history and current evaluation of the clinical picture, the psychiatrist and his patient consider the risk of mania to overcome the antidepressant benefits of therapeutic SD.

\section{Mechanism of Action}

Despite the fact that the literature tends to emphasize the specificity of drug actions, defined as the exclusive interaction with a single critical target, many effective treatments target several mechanisms and a multitarget approach to treatment could be better suited for a multifactorial illness such as depression [129]. The mechanism of action of SD is multitarget in nature, and involves multiple and powerful effects on known targets for psychiatric antidepressant treatment [5]. Most probably, all these mechanisms contribute to the clinical outcome and help to explain the impressive rapidity and efficacy of this technique.

Regarding monoamines, converging evidence from preclinical studies and in vivo studies in depressed patients showed that SD potentiates neurotransmission based on serotonin [130,131], noradrenaline [132-134] and dopamine [11]. Biological factors affecting the activity of these pathways, such as genotypic variants $[51,135-$ 137], basal neurotransmitter levels [138], or the extent of receptor occupancy [139], affect the clinical response, thus confirming a critical role for changes in monoaminergic neurotransmission in the clinical effect of SD. 
Moreover, SD increases the levels of thyroid hormones $[140,141]$, and interacts with emerging specific targets for the treatment of mood disorders such as glycogen synthase kinase $3 \beta$ [142], glutamate [143] and the sleep-related mechanisms which regulate synaptic homeostasis [144].

The clinical effects of SD are paralleled by specific effects of SD on the brain. An impressive group of brainimaging studies with different techniques consistently showed that the antidepressant response to SD is associated with specific functional and metabolic changes in specific brain areas. In particular, major changes are observed in the general location of the ventral/anterior cingulate cortex and medial prefrontal cortex, with responders to SD showing increased relatively localized metabolic activity compared with nonresponders or normal controls at baseline: the higher the baseline levels, the greater the decrease induced by SD and the better the antidepressant effect $[13,14,72,145]$. The metabolic changes after SD are paralleled by a decrease in perfusion of the cingulate [146] and amygdala [147], which is specific of response to treatment, by changes in spectroscopic correlates of glutamatergic activity in the cingulate [143] and changes in neural correlates of brain activity in response to tasks targeting the typical depressive negative cognitive distortions [51].

These results are consistent with measurements of metabolic activity in major depression at baseline and after recovery, which showed higher metabolic rates in the perigenual cingulate at baseline and a decrease after pharmacological treatment that was proportional to the clinical amelioration $[148,149]$. In a pivotal study, similar changes were obtained in the same subjects with a single SD and with a 1-month paroxetine treatment course [150].

\section{Comparative Efficacy}

Acute response rates to SD range, depending on reported estimates, from roughly one half to three quarters of patients, similar to those reported for drug treatments $[2,17]$. Given that at least $40 \%$ of patients treated for depression do not respond to the initial trial of antidepressant drug medication [151], and that at least one half of this percentage do not respond satisfactorily to several further treatment trials [152], SD should be considered among the first-line antidepressant strategies for mood disorders.

In the acute treatment of a major depressive episode, the few trials which compared treatment with antidepres- sant drugs alone or combined with SD suggested that the main benefit obtained with SD is the hastening of antidepressant response $[45,78,82]$. This effect is obtained by combining SD with drugs soon at the beginning of treatment [45], thus skipping the usual 2 weeks' period of latency of action of antidepressant drugs.

In the long term, treatment of patients affected by bipolar depression with SD and lithium or with antidepressant drugs leads to comparable rates of sustained remission $[47,50]$, but with the obvious benefit of overcoming the need of unwieldy maintenance treatment with antidepressants, which leads to the dilemma of choosing between a high risk of relapse in the absence of a maintenance treatment with antidepressants [153], and the risk of developing treatment-induced mania, observed in roughly one quarter of bipolar patients receiving combined antidepressant drugs [123].

\section{Conclusions}

In recent years, a growing body of literature on the safety and efficacy of SD in everyday psychiatric clinical settings and the biological underpinnings of its action support the inclusion of this technique among the firstline antidepressant strategies for mood-disordered patients [9]. This technique has passed the experimental developmental phase and reached the status of a powerful and affordable clinical intervention for everyday clinical treatment of depressed patients.

Some issues need further research. In particular, the available literature does not allow (1) dose-response relationships among duration, timing and repetition of wake and antidepressant effects to be defined and (2) comparative assessment of the efficacy of the different techniques proposed over the decades (single vs. repeated, total vs. partial SD). Nevertheless, all the proposed techniques share a similar therapeutic status in terms of efficacy and favorable side effect profile, and can thus be freely chosen by the clinical psychiatrists following evaluation of the patient's psychopathological condition and clinical needs. 


\section{References}

$>1$ Benedetti F, Barbini B, Colombo C, Smeraldi 16 Leibenluft E, Wehr TA: Is sleep deprivation E: Chronotherapeutics in a psychiatric ward. Sleep Med Rev 2007;11:509-522.

$\checkmark 2$ Wirz-Justice A, Benedetti F, Berger M, Lam RW, Martiny K, Terman M, Wu JC: Chronotherapeutics (light and wake therapy) in affective disorders. Psychol Med 2005;35:939944.

3 Wirz-Justice A, Terman M, Oren DA, Goodwin FK, Kripke DF, Whybrow PC, Wisner KL, Wu JC, Lam RW, Berger M, Danilenko KV, Kasper S, Smeraldi E, Takahashi K, Thompson C, van den Hoofdakker RH: Brightening depression. Science 2004;303: 467-469.

4 Pflug B, Tolle R: Nervenarzt 1971;42:117124.

$>5$ Benedetti F, Smeraldi E: Neuroimaging and genetics of antidepressant response to sleep deprivation: implications for drug development. Curr Pharmac Design 2009;15:26372649.

-6 Wu JC, Bunney WE: The biological basis of an antidepressant response to sleep deprivation and relapse: review and hypothesis. Am J Psychiatry 1990;147:14-21.

7 Bhattacharjee Y: Psychiatric research. Is internal timing key to mental health? Science 2007;317:1488-1490.

$>8$ Harvey AG: Sleep and circadian rhythms in bipolar disorder: seeking synchrony, harmony, and regulation. Am J Psychiatry 2008; 165:820-829.

9 Wirz-Justice A, Benedetti F, Terman M: Chronotherapeutics for Affective Disorders. A Clinician's Manual for Light and Wake Therapy. Basel, Karger, 2009.

$>10$ Wirz-Justice A, Van den Hoofdakker RH: Sleep deprivation in depression: what do we know, where do we go? Biol Psychiatry 1999; 46:445-453.

11 Ebert D, Berger M: Neurobiological similarities in antidepressant sleep deprivation and psychostimulant use: a psychostimulant theory of antidepressant sleep deprivation. Psychopharmacology (Berl) 1998;140:1-10.

$>12$ Adrien J: Neurobiological bases for the relation between sleep and depression. Sleep Med Rev 2002;6:341-351.

$>13$ Gillin JC, Buchsbaum M, Wu J, Clark C, Bunney W Jr: Sleep deprivation as a model experimental antidepressant treatment: findings from functional brain imaging. Depress Anxiety 2001;14:37-49.

- 14 Wu JC, Buchsbaum M, Bunney WE Jr: Clinical neurochemical implications of sleep deprivation's effects on the anterior cingulate of depressed responders. Neuropsychopharmacology 2001;25:S74-S78.

15 Bunney JN, Potkin SG: Circadian abnormalities, molecular clock genes and chronobiological treatments in depression. Br Med Bull 2008;86:23-32. useful in the treatment of depression? Am J Psychiatry 1992;149:159-168. sleep deprivation in depression. Sleep Med Rev 2002;6:361-377.

18 Schulte W: Sequelae of sleep deprivation. Med Klin (Munich) 1959;54:969-973.

19 Benedetti F, Fresi F, Maccioni P, Smeraldi E: Behavioural sensitization to repeated sleep deprivation in a mice model of mania. Behav Brain Res 2008;187:221-227.

20 Selvi Y, Gulec M, Agargun MY, Besiroglu L: Mood changes after sleep deprivation in morningness-eveningness chronotypes in healthy individuals. J Sleep Res 2007;16:241244

21 Cole MG, Muller HF: Sleep deprivation in the treatment of elderly depressed patients. J Am Geriatr Soc 1976;24:308-313.

22 Demet EM, Chicz-Demet A, Fallon JH, Sokolski KN: Sleep deprivation therapy in depressive illness and Parkinson's disease. Prog Neuropsychopharmacol Biol Psychiatry 1999;23:753-784.

23 Fahndrich E: Sleep deprivation therapy of depressive syndromes in schizophrenic disorders (in German). Nervenarzt 1982;53: 279-293.

24 Parry BL, Curran ML, Stuenkel CA, Yokimozo M, Tam L, Powell KA, Gillin JC: Can critically timed sleep deprivation be useful in pregnancy and postpartum depressions? J Affect Disord 2000;60:201-212.

25 Parry BL, Cover H, Mostofi N, LeVeau B, Sependa PA, Resnick A, Gillin JC: Early versus late partial sleep deprivation in patients with premenstrual dysphoric disorder and normal comparison subjects. Am J Psychiatry 1995;152:404-412.

26 Vogel GW, Thurmond A, Gibbons P, Sloan $\mathrm{K}$, Walker M: REM sleep reduction effects on depression syndromes. Arch Gen Psychiatry 1975;32:765-777.

27 Barbini B, Colombo C, Benedetti F, Campori E, Bellodi L, Smeraldi E: The unipolar-bipolar dichotomy and the response to sleep deprivation. Psychiatry Res 1998;79:43-50.

$\checkmark 28$ King BH, Baxter LR Jr, Stuber M, Fish B: Therapeutic sleep deprivation for depression in children. J Am Acad Child Adolesc Psychiatry 1987;26:928-931.

29 Hernandez CR, Smith GS, Houck PR, Pollock BG, Mulsant B, Dew MA, Reynolds CF 3rd: The clinical response to total sleep deprivation and recovery sleep in geriatric depression: potential indicators of antidepressant treatment outcome. Psychiatry Res 2000;97:41-49.

30 Gillin JC: The sleep therapies of depression. Prog Neuropsychopharmacol Biol Psychiatry 1983;7:351-364.

31 Haug HJ, Fahndrich E: A turning point for mood during sleep deprivation therapy does it exist? Pharmacopsychiatry 1988;21: 418-419.
17 Giedke H, Schwarzler F: Therapeutic use of
32 Wehr TA, Rosenthal NE, Sack DA, Gillin JC: Antidepressant effects of sleep deprivation in bright and dim light. Acta Psychiatr Scand 1985;72:161-165.

33 Riemann D, Wiegand M, Lauer CJ, Berger M: Naps after total sleep deprivation in depressed patients: are they depressiogenic? Psychiatry Res 1993;49:109-120.

34 Hemmeter U, Bischof R, Hatzinger M, Seifritz E, Holsboer-Trachsler E: Microsleep during partial sleep deprivation in depression. Biol Psychiatry 1998;43:829-839.

35 Gillin JC, Kripke DF, Janowsky DS, Risch SC: Effects of brief naps on mood and sleep in sleep-deprived depressed patients. Psychiatry Res 1989;27:253-265.

36 Wiegand M, Riemann D, Schreiber W, Lauer CJ, Berger M: Effect of morning and afternoon naps on mood after total sleep deprivation in patients with major depression. Biol Psychiatry 1993;33:467-476.

37 Schilgen B, Tolle R: Partial sleep deprivation as therapy for depression. Arch Gen Psychiatry 1980;37:267-271.

38 Kuhs H, Tolle R: Sleep deprivation therapy. Biol Psychiatry 1991;29:1129-1148.

39 Giedke H, Wormstall H, Haffner HT: Therapeutic sleep deprivation in depressives, restricted to the two nocturnal hours between 3:00 and 5:00. Prog Neuropsychopharmacol Biol Psychiatry 1990;14:37-47.

40 Sack DA, Duncan W, Rosenthal NE, Mendelson WE, Wehr TA: The timing and duration of sleep in partial sleep deprivation therapy of depression. Acta Psychiatr Scand 1988;77: 219-224.

41 Giedke H, Geilenkirchen R, Hauser M: The timing of partial sleep deprivation in depression. J Affect Disord 1992;25:117-128.

42 Vogel GW, Vogel F, McAbee RS, Thurmond AJ: Improvement of depression by REM sleep deprivation. New findings and a theory. Arch Gen Psychiatry 1980;37:247-253.

43 Grozinger M, Kogel P, Roschke J: Effects of REM sleep awakenings and related wakening paradigms on the ultradian sleep cycle and the symptoms in depression. J Psychiatr Res 2002;36:299-308.

44 Vogel GW, Buffenstein A, Minter K, Hennessey A: Drug effects on REM sleep and on endogenous depression. Neurosci Biobehav Rev 1990;14:49-63.

45 Benedetti F, Barbini B, Lucca A, Campori E, Colombo C, Smeraldi E: Sleep deprivation hastens the antidepressant action of fluoxetine. Eur Arch Psychiatry Clin Neurosci 1997;247:100-103.

46 Smeraldi E, Benedetti F, Barbini B, Campori E, Colombo C: Sustained antidepressant effect of sleep deprivation combined with pindolol in bipolar depression - a placebo-controlled trial. Neuropsychopharmacology 1999;20:380-385. 
-47 Benedetti F, Colombo C, Barbini B, Campori E, Smeraldi E: Ongoing lithium treatment prevents relapse after total sleep deprivation. J Clin Psychopharmacol 1999;19:240-245.

$\checkmark 48$ Colombo C, Lucca A, Benedetti F, Barbini B, Campori E, Smeraldi E: Total sleep deprivation combined with lithium and light therapy in the treatment of bipolar depression: replication of main effects and interaction. Psychiatry Res 2000;95:43-53.

-49 Benedetti F, Campori E, Barbini B, Fulgosi $\mathrm{MC}$, Colombo C: Dopaminergic augmentation of sleep deprivation effects in bipolar depression. Psychiatry Res 2001;104:239246.

-50 Benedetti F, Barbini B, Fulgosi MC, Colombo C, Dallaspezia S, Pontiggia A, Smeraldi E: Combined total sleep deprivation and light therapy in the treatment of drug-resistant bipolar depression: acute response and longterm remission rates. J Clin Psychiatry 2005; 66:1535-1540.

51 Benedetti F, Bernasconi A, Blasi V, Cadioli M, Colombo C, Falini A, Lorenzi C, Radaelli D, Scotti G, Smeraldi E: Neural and genetic correlates of antidepressant response to sleep deprivation: a fMRI study of moral valence decision in bipolar depression. Arch Gen Psychiatry 2007;64:179-187.

$\checkmark 52$ Benedetti F, Dallaspezia S, Fulgosi MC, Barbini B, Colombo C, Smeraldi E: Phase advance is an actimetric correlate of antidepressant response to sleep deprivation and light therapy in bipolar depression. Chronobiol Int 2007;24:921-937.

-53 Telger K, Tolle R, Fischer H: Repeating antidepressive sleep deprivation therapy (partial sleep deprivation) (in German). Psychiatr Prax 1990;17:121-125.

54 Holsboer-Trachsler E, Ernst K: Sustained antidepressive effect of repeated partial sleep deprivation. Psychopathology 1986;19(suppl 2):172-176.

-55 Leibenluft E, Moul DE, Schwartz PJ, Madden PA, Wehr TA: A clinical trial of sleep deprivation in combination with antidepressant medication. Psychiatry Res 1993; 46:213-227.

-56 Caliyurt O, Guducu F: Partial sleep deprivation therapy combined with sertraline affects subjective sleep quality in major depressive disorder. Sleep Med 2005;6:555559.

-57 Dessauer M, Goetze U, Tolle R: Periodic sleep deprivation in drug-refractory depression. Neuropsychobiology 1985;13:111-116.

58 Kuhs H, Farber D, Borgstadt S, Mrosek S, Tolle R: Amitriptyline in combination with repeated late sleep deprivation versus amitriptyline alone in major depression. A randomised study. J Affect Disord 1996;37:3141.

-59 van den Burg W, van den Hoofdakker RH: Total sleep deprivation on endogenous depression. Arch Gen Psychiatry 1975;32:11211125.
60 Wiegand MH, Lauer CJ, Schreiber W: Patterns of response to repeated total sleep deprivations in depression. J Affect Disord 2001;64:257-260.

61 Kundermann B, Strate P, Hemmeter-Spernal J, Huber MT, Krieg JC, Lautenbacher S: Midterm effects of serial sleep deprivation therapy implemented in cognitive-behavioral treatment on the neuroendocrine response to clomipramine in patients with major depression. J Psychiatr Res 2009;43:711-720.

62 Papadimitriou GN, Christodoulou GN, Trikkas GM, Malliaras DE, Lykouras EP, Stefanis CN: Sleep deprivation psychoprophylaxis in recurrent affective disorders. Bibl Psychiatr 1981;56-61.

63 van Bemmel AL, van den Hoofdakker RH: Maintenance of therapeutic effects of total sleep deprivation by limitation of subsequent sleep. A pilot study. Acta Psychiatr Scand 1981;63:453-462.

64 Christodoulou GN, Malliaras DE, Lykouras EP, Papadimitriou GN, Stefanis CN: Possible prophylactic effect of sleep deprivation. Am J Psychiatry 1978;135:375-376.

65 Papadimitriou GN, Christodoulou GN, Katsouyanni K, Stefanis CN: Therapy and prevention of affective illness by total sleep deprivation. J Affect Disord 1993;27:107116.

66 Kuhs H, Kemper B, Lippe-Neubauer U, Meyer-Dunker J, Tolle R: Repeated sleep deprivation once versus twice a week in combination with amitriptyline. J Affect Disord 1998;47: 97-103.

67 Baving L, Maes H, Bohus M, Lis S, Krieger S, Olbrich $\mathrm{H}$, Berger M: Can negative selfschemes in depressives be altered through sleep deprivation? J Affect Disord 1997;42: 93-101.

68 Benedetti F, Barbini B, Florita M, Cigala Fulgosi M, Campori E, Colombo C, Smeraldi E: Rapid improvement in information processing after sleep deprivation and sleep phaseadvance in bipolar depression. Clin Psychiatry 2005;2:180-182.

69 Bump GM, Reynolds CF 3rd, Smith G, Pollock BG, Dew MA, Mazumdar S, Geary M, Houck PR, Kupfer DJ: Accelerating response in geriatric depression: a pilot study combining sleep deprivation and paroxetine. Depress Anxiety 1997;6:113-118.

-70 Green TD, Reynolds CF 3rd, Mulsant BH, Pollock BG, Miller MD, Houck PR, Mazumdar S, Dew MA, Kupfer DJ: Accelerating antidepressant response in geriatric depression: a post hoc comparison of combined sleep deprivation and paroxetine versus monotherapy with paroxetine, nortriptyline, or placebo. J Geriatr Psychiatry Neurol 1999;12:67-71.

71 Caliyurt O, Guducu F: Partial sleep deprivation therapy combined with sertraline induces more rapid improvements in quality of life items in major depressive disorder. J Affect Disord 2005;88:75-78.
$2 \mathrm{Wu}$ JC, Gillin JC, Buchsbaum MS, Schachat C, Darnall LA, Keator DB, Fallon JH, Bunney WE: Sleep deprivation PET correlations of Hamilton symptom improvement ratings with changes in relative glucose metabolism in patients with depression. J Affect Disord 2008;107:181-186.

73 Wirz-Justice A, Puhringer W, Hole G: Sleep deprivation and clomipramine in endogenous depression. Lancet 1976;ii:912.

74 Loosen PT, Merkel U, Amelung U: Letter: combined sleep deprivation and clomipramine in primary depression. Lancet 1976;ii:156-157.

75 Elsenga S, van den Hoofdakker RH: Clinical effects of sleep deprivation and clomipramine in endogenous depression. J Psychiatr Res 1982;17:361-374

76 Fahndrich E: Effect of sleep deprivation as a predictor of treatment response to antidepressant medication. Acta Psychiatr Scand 1983;68:341-344.

-77 Berger M, Vollmann J, Hohagen F, Konig A, Lohner H, Voderholzer U, Riemann D: Sleep deprivation combined with consecutive sleep phase advance as a fast-acting therapy in depression: an open pilot trial in medicated and unmedicated patients. Am J Psychiatry $1997 ; 154: 870-872$

78 Shelton RC, Loosen PT: Sleep deprivation accelerates the response to nortriptyline. Prog Neuropsychopharmacol Biol Psychiatry 1993;17:113-123

79 Holsboer-Trachsler E, Hemmeter U, Hatzinger M, Seifritz E, Gerhard U, Hobi V: Sleep deprivation and bright light as potential augmenters of antidepressant drug treatment - neurobiological and psychometric assessment of course. J Psychiatr Res 1994;28:381-399.

80 Grunze H, Erfurth A, Walden J: Trimipramine fails to exert antimanic efficacy: a case of the discrepancy between in vitro rationale and clinical efficacy. Clin Neuropharmacol 1999;22:298-300.

-81 Baxter LR Jr: Can lithium carbonate prolong the antidepressant effect of sleep deprivation? Arch Gen Psychiatry 1985;42:635.

82 Baxter LR Jr, Liston EH, Schwartz JM, Altshuler LL, Wilkins JN, Richeimer S, Guze $\mathrm{BH}$ : Prolongation of the antidepressant response to partial sleep deprivation by lithium. Psychiatry Res 1986;19:17-23.

83 Benedetti F, Barbini B, Bernasconi A, Fulgosi MC, Campori E, Colombo C, Dallaspezia S, Lorenzi C, Pontiggia A, Radaelli D, Smeraldi E: Lithium overcomes the influence of 5-HTTLPR gene polymorphism on antidepressant response to sleep deprivation. J Clin Psychopharmacol 2008;28:249251.

84 van den Burg W, Bouhuys AL, van den Hoofdakker RH, Beersma DG: Sleep deprivation in bright and dim light: Antidepressant effects on major depressive disorder. J Affect Disord 1990;19:109-117. 
-85 Neumeister A, Goessler R, Lucht M, Kapitany T, Bamas C, Kasper S: Bright light therapy stabilizes the antidepressant effect of partial sleep deprivation. Biol Psychiatry 1996;39: $16-21$.

-86 Benedetti F, Barbini B, Campori E, Fulgosi MC, Pontiggia A, Colombo C: Sleep phase advance and lithium to sustain the antidepressant effect of total sleep deprivation in bipolar depression: new findings supporting the internal coincidence model? J Psychiatr Res 2001;35:323-329.

87 Riemann D, Konig A, Hohagen F, Kiemen A, Voderholzer U, Backhaus J, Bunz J, Wesiack B, Hermle L, Berger M: How to preserve the antidepressive effect of sleep deprivation: a comparison of sleep phase advance and sleep phase delay. Eur Arch Psychiatry Clin Neurosci 1999;249:231-237.

$>88$ Voderholzer U, Valerius G, Schaerer L, Riemann D, Giedke H, Schwarzler F, Berger M, Wiegand M: Is the antidepressive effect of sleep deprivation stabilized by a three-day phase advance of the sleep period? A pilot study. Eur Arch Psychiatry Clin Neurosci 2003;253:68-72.

-89 Vollmann J, Berger M: Sleep deprivation with consecutive sleep-phase advance therapy in patients with major depression: a pilot study. Biol Psychiatry 1993;33:54-57.

90 Elsenga S, Van den Hoofdakker RH: Response to total sleep deprivation and clomipramine in endogenous depression. J Psychiatr Res 1987;21:151-161.

-91 Elsenga S, Beersma D, Van den Hoofdakker RH: Total and partial sleep deprivation in clomipramine-treated endogenous depressives. J Psychiatr Res 1990;24:111-119.

\$2 Fahndrich E: Effects of sleep deprivation on depressed patients of different nosological groups. Psychiatry Res 1981;5:277-285.

93 King D, Dowdy S, Jack R, Gardner R, Edwards P: The dexamethasone suppression test as a predictor of sleep deprivation antidepressant effect. Psychiatry Res 1982;7:9399.

94 Elsenga S, Van den Hoofdakker RH: Antidepressant medication and total sleep deprivation in depressives; in Bunney WE, Hippius H, Laakman G, Schnauss M (eds): Neuropsychopharmacology. Berlin, Springer Verlag, 1990, pp 639-651.

95 Benedetti F, Zanardi R, Colombo C, Smeraldi E: Worsening of delusional depression after sleep deprivation: case reports. J Psychiatr Res 1999;33:69-72.

96 Sachs GS, Thase ME: Bipolar disorder therapeutics: maintenance treatment. Biol Psychiatry 2000;48:573-581.

97 Kruger S, Trevor Young L, Braunig P: Pharmacotherapy of bipolar mixed states. Bipolar Disord 2005;7:205-215.

$\$ 98$ Strouse TB, Szuba MP, Baxter LR Jr: Response to sleep deprivation in three women with postpartum psychosis. J Clin Psychiatry 1992;53:204-206.
99 Ross LE, Murray BJ, Steiner M: Sleep and perinatal mood disorders: a critical review. J Psychiatry Neurosci 2005;30:247-256.

100 McEwen BS: Sleep deprivation as a neurobiologic and physiologic stressor: allostasis and allostatic load. Metabolism 2006; 55:S20-S23.

101 Delva NJ, Woo M, Southmayd SE, Hawken ER: Myocardial infarction during sleep deprivation in a patient with dextrocardia a case report. Angiology 2001;52:83-86.

102 Suh SY, Kim JW, Choi CU, Kim EJ, Rha SW, Park CG, Seo HS, Oh DJ: Spontaneous coronary dissection associated with sleep deprivation presenting with acute myocardial infarction. Int J Cardiol 2007;115:e78-e79.

103 Dinner DS: Effect of sleep on epilepsy. J Clin Neurophysiol 2002;19:504-513.

104 Romcy-Pereira RN, Leite JP, Garcia-Cairasco N: Synaptic plasticity along the sleepwake cycle: implications for epilepsy. Epilepsy Behav 2009;14(suppl 1):47-53.

105 Roy-Byrne P, Uhde TW, Post RM, Joffe RT: Relationship of response to sleep deprivation and carbamazepine in depressed patients. Acta Psychiatr Scand 1984;69:379382.

106 Chen H, Schernhammer E, Schwarzschild MA, Ascherio A: A prospective study of night shift work, sleep duration, and risk of parkinson's disease. Am J Epidemiol 2006; 163:726-730.

107 Levin Ia I: Effects of sleep deprivation in patients with parkinsonism (in Russian). Sov Med 1991;9-11.

108 Reist C, Sokolski KN, Chen CC, Coskinas E, Demet EM: The effect of sleep deprivation on motor impairment and retinal adaptation in Parkinson's disease. Prog Neuropsychopharmacol Biol Psychiatry 1995; 19:445-454.

109 Hogl B, Peralta C, Wetter TC, Gershanik O, Trenkwalder C: Effect of sleep deprivation on motor performance in patients with Parkinson's disease. Mov Disord 2001;16:616621.

110 Bertolucci PH, Andrade LA, Lima JG, Carlini EA: Total sleep deprivation and Parkinson disease. Arq Neuropsiquiatr 1987;45: 224-230.

111 Lauterbach EC: Sleep benefit and sleep deprivation in subgroups of depressed patients with Parkinson's disease. Am J Psychiatry 1994;151:782-783.

- 112 Wilkie G, Shapiro CM: Sleep deprivation and the postnatal blues. J Psychosom Res 1992;36:309-316.

113 Okun ML, Coussons-Read ME: Sleep disruption during pregnancy: how does it influence serum cytokines? J Reprod Immunol 2007;73:158-165.

114 Okun ML, Hall M, Coussons-Read ME: Sleep disturbances increase interleukin-6 production during pregnancy: Implications for pregnancy complications. Reprod Sci 2007;14:560-567.
115 Studwell J: All sleepless and light. Financial Times Magazine 2004;23:20-25.

116 Hemmeter U, Hatzinger M, Brand S, Holsboer-Trachsler E: Effect of flumazenil-augmentation on microsleep and mood in depressed patients during partial sleep deprivation. J Psychiatr Res 2007;41:876-884.

117 Wehr TA, Sack DA, Norman E: Sleep reduction as a final common pathway in the genesis of mania. Am J Psychiatry 1987;144: 201-204.

118 Wehr TA: Improvement of depression and triggering of mania by sleep deprivation. JAMA 1992;267:548-551.

119 Wehr TA, Goodwin FK, Wirz-Justice A, Breitmaier J, Craig C: 48-Hour sleep-wake cycles in manic-depressive illness: naturalistic observations and sleep deprivation experiments. Arch Gen Psychiatry 1982;39: 559-565.

120 Colombo C, Benedetti F, Barbini B, Campori E, Smeraldi E: Rate of switch from depression into mania after therapeutic sleep deprivation in bipolar depression. Psychiatry Res 1999;86:267-270.

121 Peet M: Induction of mania with selective serotonin re-uptake inhibitors and tricyclic antidepressants. Br J Psychiatry 1994;164: 549-550.

122 Post RM, Altshuler LL, Leverich GS, Frye MA, Nolen WA, Kupka RW, Suppes T, McElroy S, Keck PE, Denicoff KD, Grunze H, Walden J, Kitchen CM, Mintz J: Mood switch in bipolar depression: comparison of adjunctive venlafaxine, bupropion and sertraline. Br J Psychiatry 2006;189:124-131.

123 Frye MA, Helleman G, McElroy SL, Altshuler LL, Black DO, Keck PE Jr, Nolen WA, Kupka R, Leverich GS, Grunze H, Mintz J, Post RM, Suppes T: Correlates of treatment-emergent mania associated with antidepressant treatment in bipolar depression. Am J Psychiatry 2009;166:164-172.

124 Wehr TD, Sack DA: Sleep distruption: a treatment for depression and a cause of mania. Psychiatric Ann 1987;17:654-663.

125 Wehr TA: Sleep loss: a preventable cause of mania and other excited states. J Clin Psychiatry 1989;50(suppl):8-16; discussion 45-17.

126 Wehr TA: Sleep-loss as a possible mediator of diverse causes of mania. Br J Psychiatry 1991; 159:576-578.

127 Barbini B, Bertelli S, Colombo C, Smeraldi E: Sleep loss, a possible factor in augmenting manic episode. Psychiatry Res 1996;65: 121-125.

128 Barbini B, Benedetti F, Colombo C, Dotoli D, Bernasconi A, Cigala-Fulgosi M, Florita M, Smeraldi E: Dark therapy for mania: a pilot study. Bipolar Disord 2005;7:98-101.

129 Millan MJ: Multi-target strategies for the improved treatment of depressive states: conceptual foundations and neuronal substrates, drug discovery and therapeutic application. Pharmacol Ther 2006;110:135370 . 
130 Gardner JP, Fornal CA, Jacobs BL: Effects of sleep deprivation on serotonergic neuronal activity in the dorsal raphe nucleus of the freely moving cat. Neuropsychopharmacology 1997;17:72-81.

131 Salomon RM, Delgado PL, Licinio J, Krystal JH, Heninger GR, Charney DS: Effects of sleep deprivation on serotonin function in depression. Biol Psychiatry 1994;36: 840-846.

132 Amin MM, Khalid R, Khan P: Relationship between sleep deprivation and urinary MHPG levels. Int Pharmacopsychiatry 1980;15:81-85.

133 Matussek N, Romisch P, Ackenheil M: MHPG excretion during sleep deprivation in endogenous depression. Neuropsychobiology 1977;3:23-29.

134 Muller HU, Riemann D, Berger M, Muller WE: The influence of total sleep deprivation on urinary excretion of catecholamine metabolites in major depression. Acta Psychiatr Scand 1993;88:16-20.

135 Benedetti F, Serretti A, Colombo C, Campori E, Barbini B, Di Bella D, Smeraldi E: Influence of a functional polymorphism within the promoter of the serotonin transporter gene on the effects of total sleep deprivation in bipolar depression. Am J Psychiatry 1999;156:1450-1452.

136 Benedetti F, Colombo C, Serretti A, Lorenzi C, Pontiggia A, Barbini B, Smeraldi E: Antidepressant effects of light therapy combined with sleep deprivation are influenced by a functional polymorphism within the promoter of the serotonin transporter gene. Biol Psychiatry 2003;54:687-692.

137 Benedetti F, Barbini B, Bernasconi A, Fulgosi MC, Colombo C, Dallaspezia S, Gavinelli C, Marino E, Pirovano A, Radaelli D, Smeraldi E: Serotonin $5-\mathrm{HT}_{2 \mathrm{a}}$ receptor gene variants influence antidepressant response to repeated total sleep deprivation in bipolar depression. Prog Neuropsychopharmacol Biol Psychiatry 2008;32:18631866.
138 Gerner RH, Post RM, Gillin JC, Bunney WE Jr: Biological and behavioral effects of one night's sleep deprivation in depressed patients and normals. J Psychiatr Res 1979; 15:21-40.

139 Ebert D, Feistel H, Kaschka W, Barocka A, Pirner A: Single photon emission computerized tomography assessment of cerebral dopamine D2 receptor blockade in depression before and after sleep deprivation preliminary results. Biol Psychiatry 1994; 35:880-885

140 Parekh PI, Ketter TA, Altshuler L, Frye MA, Callahan A, Marangell L, Post RM: Relationships between thyroid hormone and antidepressant responses to total sleep deprivation in mood disorder patients. Biol Psychiatry 1998;43:392-394.

141 Szuba MP, Altshuler LL, Baxter LR Jr: Thyroid function and partial sleep deprivation response. Arch Gen Psychiatry 1992;49: 581-582.

142 Benedetti F, Serretti A, Colombo C, Lorenzi C, Tubazio V, Smeraldi E: A glycogen synthase kinase 3-beta promoter gene single nucleotide polymorphism is associated with age at onset and response to total sleep deprivation in bipolar depression. Neurosci Lett 2004;368:123-126.

143 Benedetti F, Calabrese G, Bernasconi A, Cadioli M, Colombo C, Dallaspezia S, Falini A, Radaelli D, Scotti G, Smeraldi E: Spectroscopic correlates of antidepressant response to sleep deprivation and light therapy: A 3.0 tesla study of bipolar depression. Psychiatry Res 2009;173:238-242.

144 Tononi G, Cirelli C: Sleep function and synaptic homeostasis. Sleep Med Rev 2006;10: 49-62.

145 Wu JC, Gillin JC, Buchsbaum MS, Hershey T, Hazlett E, Sicotte N, Bunney WE Jr: The effect of sleep deprivation on cerebral glucose metabolic rate in normal humans assessed with positron emission tomography. Sleep 1991;14:155-162.

146 Clark CP, Brown GG, Frank L, Thomas L, Sutherland AN, Gillin JC: Improved anatomic delineation of the antidepressant response to partial sleep deprivation in medial frontal cortex using perfusion-weighted functional MRI. Psychiatry Res 2006; 146:213-222.
147 Clark CP, Brown GG, Archibald SL, Fennema-Notestine C, Braun DR, Thomas LS, Sutherland AN, Gillin JC: Does amygdalar perfusion correlate with antidepressant response to partial sleep deprivation in major depression? Psychiatry Res 2006;146: 43-51.

148 Mayberg HS, Liotti M, Brannan SK, McGinnis S, Mahurin RK, Jerabek PA, Silva JA, Tekell JL, Martin CC, Lancaster JL, Fox PT: Reciprocal limbic-cortical function and negative mood: converging PET findings in depression and normal sadness. Am J Psychiatry 1999;156:675-682.

149 Mayberg HS: Modulating dysfunctional limbic-cortical circuits in depression: towards development of brain-based algorithms for diagnosis and optimised treatment. Br Med Bull 2003;65:193-207.

150 Smith GS, Reynolds CF 3rd, Pollock B, Derbyshire S, Nofzinger E, Dew MA, Houck PR, Milko D, Meltzer CC, Kupfer DJ: Cerebral glucose metabolic response to combined total sleep deprivation and antidepressant treatment in geriatric depression. Am J Psychiatry 1999;156:683-689.

151 Depression guideline panel. Clinical practice guideline number 5: Depression in primary care, 2: Treatment of major depression. Rockville, Agency for Health Care Policy and Research, Public Health Service, US Dept of Health and Human Services, 1993.

152 Crown WH FS, Berndt ER: The impact of treatment resistant depression on health care utilization and costs. J Clin Psychiatry 2002;63:963-971.

153 Altshuler L, Kiriakos L, Calcagno J, Goodman R, Gitlin M, Frye M, Mintz J: The impact of antidepressant discontinuation versus antidepressant continuation on 1-year risk for relapse of bipolar depression: a retrospective chart review. J Clin Psychiatry 2001;62:612-616. 